\title{
DESAIN SARANA BERMAIN KUCING BERNUANSA ALAM
}

\author{
Andi Farid Hidayanto ${ }^{1}$ \\ ${ }^{1}$ Staf Pengajar Program Studi Desain Produk, Jurusan Desain \\ Politeknik Negeri Samarinda \\ Adinda Prita Dwisuda Putri ${ }^{2}$ \\ ${ }^{2}$ Mahasiswa Program Studi Desain Produk, Jurusan Desain \\ Politeknik Negeri Samarinda
}

\begin{abstract}
ABSTRAK
Kucing merupakan hewan yang memiliki kebutuhan naluriah untuk mengekspresikan perilaku tertentu salah satunya dengan bermain. Kucing yang terlalu lama atau selalu berada di dalam kandang tentu saja akan mengalami sifat yang lebih pendiam. Kucing sebagai hewan yang lincah tentu merindukan bermain di alam liar. Namun, bagi pecinta kucing melepaskan kucing bermain di luar rumah tentu sangat berat karena memiliki beragam resiko. Salah satu tindakan yang sering dilakukan adalah mengajak bermain di dalam rumah. Tetapi kucing tetaplah hewan yang membutuhkan suasana alam. Sarana bermain yang berada di dalam rumah tetapi memiliki fasilitas seperti di luar rumah membantu para pecinta kucing untuk mengajak kucingnya untuk bermain, sehingga diperlukan perancangan desain sarana bermain kucing.

Dengan adanya metode perencanaan dan perancangan yang sudah dilakukan diantaranya adalah pengumpulan data, analisis data, konsep desain, alternatif desain, pengembangan desain dari alternatif desain terpilih, serta desain akhir, didapatlah hasil akhir perancangan sarana bermain yaitu berupa produk yang memiliki fasilitas dan kebutuhan kucing serta memiliki suasana seperti di luar rumah dan dengan desain berbentuk jejak kaki kucing sehingga dapat menjadi komunikasi pada konsumen untuk mengetahui bahwa sarana bermain ini dikhususkan untuk kucing.

Kata kunci : Kucing, Bermain, Sarana Bermain
\end{abstract}

\begin{abstract}
Cat is an animal that has the instinctive need to express certain behaviours either by playing.Cats are too long or they are always in the cage of course will experience more reticent silent. Cats as an animal thats agile, certainly miss playing in nature But, for cat lovers release the cat to play ouside the house of course very heavy because it has a variety of risks. One of the actions is common practice to invite to play in the house. But the cat still need of nature.Playgrounds inside the house but have facillities such as outside the home to help the cat lovers to take his cat to play. So, its necessary to design the playground cat. With their methods of design and planning that has been done among the data collection, data analysis, concept design, alternative design, design development of alternative design and the final design was selected at the end of the design playground it can be the result of playing in the form of products which have the facilities and the needs of cats and has a feel like in nature and design shaped footprints of a cat. So it can be a communication on the consumer to know this playground especially to cats.
\end{abstract}

Keywords: Cats, Playing, Playground. 
Andi Farid Hidayanto, Adinda Prita Dwisuda Putri, Desain Sarana Bermain Kucing Bernuansa Alam

\section{Pendahuluan}

Kucing termasuk hewan peliharaan yang sedang digemari. Bentuknya yang unik dan menggemaskan menjadi daya tarik tersendiri. Awalnya orang dahulu memelihara kucing digunakan untuk menangkap tikus, namun seiring perkembangan zaman, kucing sekarang menjadi beragam dan lebih memikat hati para pecintanya. Sekarang banyak kucing jenis baru hasil persilangan jenis-jenis kucing dan menghasilkan kucing jenis baru yang berbeda dari induknya, yang sering disebut kucing ras. Harganya juga tinggi, karena itu sekarang mulai banyak orang memelihara kucing sebagai koleksi atau peliharaan yang disayangi, bukan untuk menangkap tikus lagi.

Kucing adalah hewan yang memiliki kebutuhan naluriah untuk mengekspresikan perilaku tertentu, salah satunya adalah dengan bermain. Kucing domestik ataupun kucing ras semua memiliki perasaan naluriah untuk bermain, sifat dan kebiasaan kucing adalah berlari saling mengejar sesama kucing atau mengejar benda yang menarik perhatiannya, mencakar-cakar, memanjat, menaiki tangga. Kucing yang terlalu lama atau selalu berada di dalam kandang akan mengalami perubahan sifat yaitu lebih pendiam. Bagi pecinta kucing mengeluarkan kucing ke alam bebas untuk bermain tentu saja hal yang beresiko. Seperti tertabrak kendaraan, hilang, berkelahi, terluka atau tertular penyakit-penyakit berbahaya yang kadang bisa menular ke manusia.
Salah satu tindakan yang sering

dilakukan oleh pecinta kucing adalah mengajaknya bermain di dalam rumah dengan menggunakan benda-benda yang menarik perhatian kucing. Bagi pecinta kucing yang memiliki dana lebih akan memberikan fasilitas lebih kepada kucing kesayangannya agar kucing tetap beraktifitas sebagaimana kucing lainnya yaitu dengan membelikan kucing tempat bermain kucing. Tetapi, kucing tetaplah hewan yang membutuhkan suasana alam, kucing juga memiliki kebiasaan berguling di pasir, di bebatuan atau di rerumputan yang berada di luar rumah. Karena, produk yang sudah ada sekarang kurang memberikan suasana seperti luar rumah dan kurangnya fasilitas bermain yang sesuai dengan kebiasaan kebiasaan kucing. Berdasarkan hal tersebut, maka diperlukan produk berupa sarana bermain kucing untuk di dalam rumah tetapi memberikan suasana seperti berada di luar rumah dan mencakup segala akifitas dan kebiasaan - kebiasaan kucing.

\section{Metode Penelitian}

Dalam perancangan ini menggunakan metode dari Bryan Lawsen, dengan langkah langkah yaitu: Perumusan masalah, tinjauan pustaka, analisis data, alternatif desain, pengembangan alternatif desain, dan desain akhir.

\section{Perumusan masalah berupa} merumuskan permasalahan yang ditemui pada sarana bermain kucing yang ada di lapangan, disesuaikan dengan kebutuhan dan aktifitas kucing yang bermain, dengan tema 
Vol. 2, No. 2, April 2015

alam luar/bebas sehingga berkesan seperti di alam sesungguhnya. Tinjauan pustaka mempelajari literatur - literatur yang ada, kemudian dianalisa untuk diambil data data yang diperlukan dalam perancangan. Alternatif desain yaitu sketsa alternatifalternaitf desain yang terdiri dari beberapa pilihan, kemudian dianalisa kelebihan/ kekuangannya sesuai dengan tema/tujuan. Dari beberapa alternatif desain selajutnya dipilih satu alternatif terpilih. Alternatif terpilih ini akan dikembangkan menjadi lebih spesifik sehinga menjadi desain final yang akan diproduksi. Desian final meliputi gambar presentasi, gambar teknis, gambar potongan, gambar detail sehinga bisa dibaca untuk diproduksi oleh tenaga produksi.

\section{Hasil dan Pembahasan}

Analisis aktivitas dan kebutuhan dilakukan untuk mengetahui aktivitas yang dilakukan berkaitan dengan produk yang akan dibuat sehingga diperoleh kebutuhan pengguna. Berdasarkan kebutuhan tersebut maka dibuat pemecahan untuk memenuhi kebutuhan yang dapat diaplikasikan pada produk.

Berdasarkan analisis aktivitas dan kebutuhan yang terdapat pada tabel 1 , maka didapatkan kesimpulan mengenai komponen-komponen apa saja yang harus ada dalam produk, ialah: (1)Memiliki tempat atau ruang untuk tidur dan berbaring, (2) Memiliki tempat khusus untuk memanjat, mencakar, bersembunyi dan bermain, (3) Memiliki tempat untuk makan dan minum, (4) Memiliki tempat khusus untuk berguling, (5) Memiliki tempat untuk membuang kotoran

Tabel 1. Aktivitas dan Kebutuhan Kucing

\begin{tabular}{|l|l|l|}
\hline No & \multicolumn{1}{|c|}{ Aktifitas } & \multicolumn{1}{c|}{ Kebutuhan } \\
\hline 1. & Tidur & Tempat untuk kucing tidur \\
\hline 2. & Memanjat & Dahan kayu untuk kucing memanjat \\
\hline 3. & Mencakar & Tiang yang dililit dengan tali kapal untuk mencakar \\
\hline 4. & Makan dan minum & $\begin{array}{l}\text { Tempat untuk meletakan wadah kucing makan dan } \\
\text { minum }\end{array}$ \\
\hline 5. & Berguling & Rumput sintetis untuk kucing berguling \\
\hline 6. & Membuang kotoran & Tempat untuk meletakan wadah kotoran \\
\hline 7. & Kucing bermain & $\begin{array}{l}\text { Area taman bermain yang dibuat sesuai dengan } \\
\text { kapasitas maksimal 3 kucing dan adanya permainan } \\
\text { menggantung untuk kucing bermain }\end{array}$ \\
\hline 8. & Kucing Bersembunyi & \begin{tabular}{l} 
Tempat untuk kucing bersembunyi \\
\hline
\end{tabular} \\
\hline
\end{tabular}


Andi Farid Hidayanto, Adinda Prita Dwisuda Putri, Desain Sarana Bermain Kucing Bernuansa Alam

Tabel 2 Aktivitas dan Kebutuhan pemilik

\begin{tabular}{|l|l|l|}
\hline No. & Aktifitas & Kebutuhan \\
\hline 1. & $\begin{array}{l}\text { Memindahkan produk sarana } \\
\text { bermain kucing }\end{array}$ & $\begin{array}{l}\text { Adanya paku sepatu rotan pada bagian } \\
\text { bawah produk }\end{array}$ \\
\hline 2. & $\begin{array}{l}\text { Memasukan dan mengeluarkan } \\
\text { kucing dari dalam kandang }\end{array}$ & $\begin{array}{l}\text { Adanya lubang pada kandang yang } \\
\text { difungsikan sebagai pintu }\end{array}$ \\
\hline
\end{tabular}

Berdasarkan analisis aktifitas dan kebutuhan yang terdapat pada tabel 2, maka didapatkan kesimpulan mengenai komponen-komponen apa saja yang harus ada dalam produk, ialah: (1) Memiliki paku sepatu rotan dibagian bawah produk sehingga dapat memudahkan saat ingin memindahkan produk sarana bermain kucing dengan cara didorong, (2) Memiliki lubang pada kandang yang difungsikan sebagai pintu untuk memasukkan dan mengeluarkan kucing

Analisis ergonomi digunakan untuk menyesuaikan suasana kerja dengan aktivitas manusia di lingkungannya, untuk mencari kesesuaian antara karakteristik pekerjaan dengan karakteristik manusianya.

Produk ini di desain untuk 2 hingga 3 ekor kucing, dan didesain aman dengan tidak adanya sudut tajam yang dapat melukai kucing saat bermain serta dilengkapi dengan berbagai macam permainan yang sesuai dengan aktifitas kucing. Produk sarana ini dapat dipindahkan dengan cara di dorong atau dapat diangkat oleh 2 orang.

Menentukan tinggi sarana bermain kucing diperoleh dari dimensi tubuh tinggi pegangan tangan pada posisi tangan vertikal ke atas pada posisi duduk. Gender yang digunakan adalah perempuan \% tile, dengan nilai yang diambil adalah 5\% tile dengan dimensi ukuran 945mm. Ukuran tersebut akan ditambah dengan toleransi. Dengan demikian tinggi sarana bermain kucing tersebut adalah $1.000 \mathrm{~mm}$

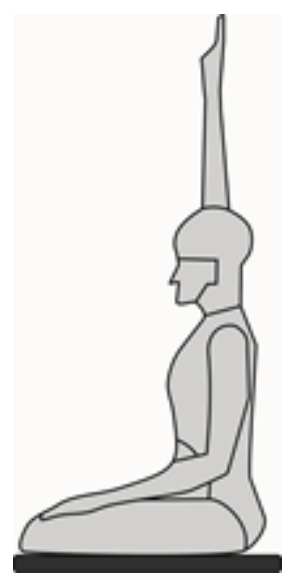

Gambar 1. Anthropometri tinggi sarana bermain

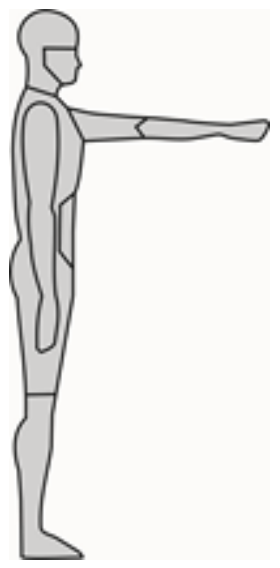

Gambar 2. Anthropometri panjang sarana bermain 
Vol. 2, No. 2, April 2015

Menentukan panjang sarana bermain kucing diperoleh dari dimensi tubuh Jarak genggam tangan ke punggung pada posisi tangan ke depan. Gender yang digunakan adalah laki-laki \% tile, yang diambil adalah 95\% tile dengan dimensi ukuran $767 \mathrm{~mm}$, ukuran tersebut akan ditambah dengan toleransi. Dengan demikian lebar sarana bermain kucing tersebut adalah $800 \mathrm{~mm}$

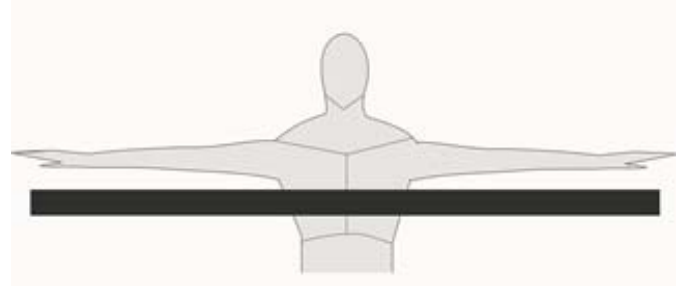

Gambar 3. Anthropometri lebar sarana bermain

Menentukan lebar sarana bermain kucing diperoleh dari dimensi tubuh Jarak bentang dari ujung jari tangan kanan ke tangan kiri. Gender yang digunakan adalah perempuan \% tile, yang diambil adalah 5\% tile dengan dimensi ukuran $1.400 \mathrm{~mm}$. Dengan demikian panjang sarana kucing tersebut adalah $1.000 \mathrm{~mm}$.

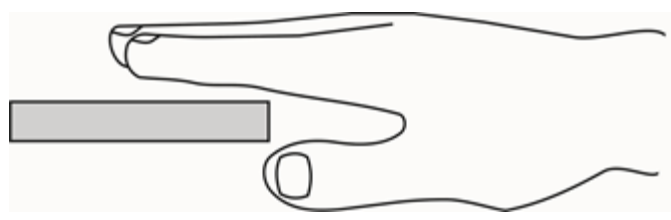

Gambar 4. Anthropometri tebal papan atas

Menentukan tebal papan atas sebagai pegangan (handle) saat ingin mendorong sarana bermain kucing diperoleh dari dimensi tubuh tebal telapak tangan sampai ibu jari. Gender yang digunakan adalah laki- laki \% tile, yang diambil adalah 95\% tile dengan dimensi ukuran $47 \mathrm{~mm}$, ukuran tersebut akan ditambah dengan toleransi. Dengan demikian tebal papan atas sebagai pegangan (handle) saat ingin mendorong tersebut adalah $40 \mathrm{~mm}$.

Menentukan lebar papan atas sebagai pegangan saat ingin memindahkan sarana bermain kucing diperoleh dari dimensi tubuh lebar bahu. Gender yang digunakan adalah laki-laki \% tile, yang diambil adalah 50\% tile dengan dimensi ukuran 424mm. Dengan demikian panjang sarana kucing tersebut adalah 400mm.

Analisis konfigurasi dilakukan untuk mendapatkan susunan atau konfigurasi dari tiap-tiap komponen yang terdapat pada produk. Dari beberapa alternatif konfigurasi, setelah dilakukan analisa kelebihan, kekurangan dan kelayakana, akhirnya ditentukan konfigurasi seperti gambar 5 dan 6 di bawah. Berikut merupakan gambaran konfigurasi produk. 


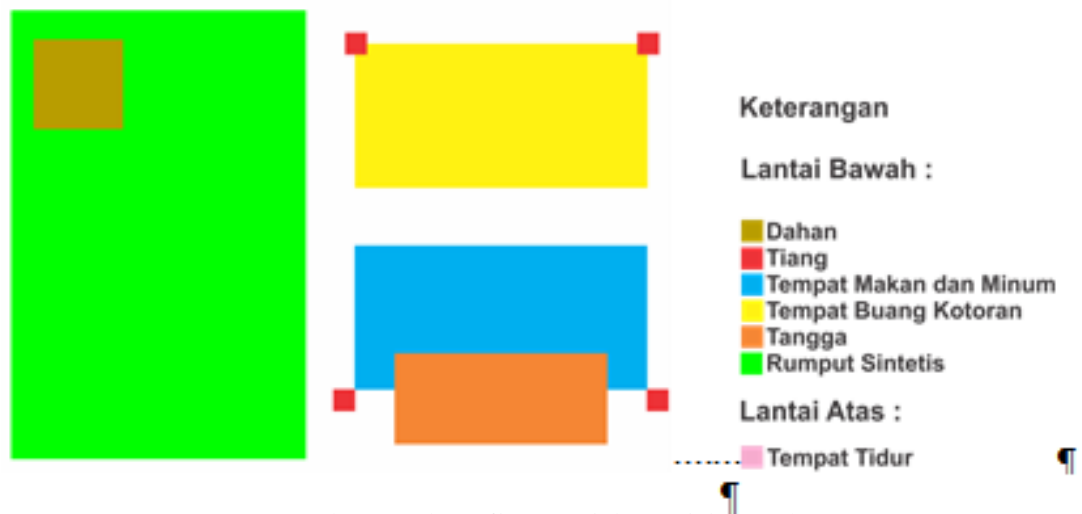

Gambar 5. konfigurasi lantai bawah

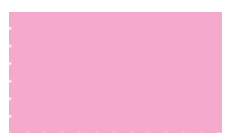

Gambar 6. konfigurasi Lantai atas

Pada konfigurasi ini memiliki 2 lantai yaitu lantai atas dan bawah. Yang membedakan adalah penempatan dahan di lantai. Tata letak dahan berada di ujung rumput sintetis, pada penempatan ini dahan diletakan diujung sehingga memberi cukup ruang untuk kucing dapat berguling-guling di rumput. Karena peletakan dahan yang berada di tepi akan memberi cukup ruang untuk kucing dapat bermain dan berguling-guling dirumput.

Aplikasi sistem dilakukan agar dapat menemukan sistem yang tepat untuk diaplikasikan pada produk. Berikut sistemsistem yang diaplikasikan pada produk, yaitu: (1) Sambungan Lekat. Sambungan lekat yang digunakan adalah lem fox atau lem putih. Karena, daya rekatnya yang kuat. Lem ini nantinya akan digunakan untuk menempelkan bebatuan pada alas plywood. (2) Sambungan Paku. Sambungan paku digunakan sebagai penyambung satu rangka dengan rangka lainnya hingga menjadi sebuah rangkaian produk, dan paku sepatu rotan digunakan sebagai alat untuk memudahkan produk pada saat ingin dipindahkan dengan cara didorong. Paku sepatu rotan diletakan atau ditancapkan dibagian bawah papan lantai utama produk sarana bermain kucing ini

Pemilihan material dilakukan agar dapat menemukan material yang tepat untuk diaplikasikan pada produk. Berikut merupakan material-material yang diaplikasikan pada produk, yaitu : (1) Kayu Lapis (Plywood). Material utama yang digunakan adalah kayu lapis plywood. Karena, merupakan produk olahan kayu yang penggunaannya sangat praktis dan mudah dibentuk daripada produk-produk sejenisnya. Plywood mempunyai ketahanan yang tinggi terhadap penyusutan sehingga bentuk dan ukurannya tidak gampang berubah, bersifat anti air atau setidaknya 
Vol. 2, No. 2, April 2015

lebih tahan dibanding produk sejenisnya dan mempunyai struktur yang kokoh sehingga cocok digunakan sebagai bahan utama dalam pembuatan produk sarana bermain ini. (2) Pipa PVC (PolyVinyl Chloride) pada umumnya digunakan sebagai saluran air dalam suatu proyek perumahan atau gedung atau jalan. Pipa PVC ini sifatnya keras, ringan, dan kuat. Pipa PVC ini diaplikasikan sebagai tiang dahan dan tiang kandang yang kemudian akan dililit oleh tali. (3) Tali Kapal. Bahan utama pembuatan tali kapal adalah serat alami. Serat ini akan dirangkai menjadi tali tambang yang terkenal karena keuletannya, keawetannya, ke-elastis-annya, kemampuan menyerap warna dan tidak hancur karena air asin. Tali kapal ini dililitkan pada tiang yang berfungsi sebagai objek sarana mencakar-cakar untuk menajamkan kuku bagi kucing. Tali kapal yang digunakan berdiameter $5 \mathrm{~mm}$. (4) Rumput sintetis (Monofilament Syntetic Grass). Tipe monofilament lebih dikenal sebagai rumput jepang. Daun rumput tipe ini kecil-kecil hampir menyerupai rumput asli dan lebih natural. Tipe rumput ini lebih disukai oleh kucing karena daya tahannya lebih kuat, lebih lembut dan permukaan rumput datar sehingga lebih enak digunakan.

(5) Batu hias. Batu hias adalah bentuk batubatuan yang dibuat dari adukan semen pasir, dibentuk dan diberi warna sedemikian rupa sehingga menyerupai batuan yang sebenarnya (alami). Batu-batu ini dipakai sebagai penghias pada produk sarana bermain ini agar menambahkan suasana luar rumah.
Finishing yang akan digunakan pada produk sarana bermain kucing ini adalah lapisan HPL dan Tacon. Lapisan HPL akan digunakan untuk melapisi rangka produk. Lapisan HPL ini memiliki tekstur seperti kayu dan cocok untuk diaplikasikan pada produk karena mengambil konsep alam. Tetapi HPLmemiliki kekurangan yaitu tidak dapat digunakan pada objek yang memiliki lengkungan. Jadi, digunakannya lapisan Tacon pada bagian yang memiliki lengkungan seperti kandang pada sarana bermain kucing ini.

Pada produk sarana bermain kucing rangka utama menggunakan lapisan dengan warna asli kayu untuk menciptakan kehangatan dan suasana natural. Kemudian adanya penambahan rumput sintetis untuk menciptakan suasana alam dan akan membuat ruangan terasa menenangkan dan nyaman.

Analisis bentuk digunakan untuk memilih bentuk jenis apa yang akan diaplikasikan pada produk. Dari beberapa alternatif bentuk modern dan post modern, serta menganalisis gaya desain yang telah dilakukan, didapat pilihan bahwa pendekatan bentuk yang cocok digunakan adalah gaya desain modern.

Dari berbagai alternatif dan analisis berbagai macam gaya desain modern yang dilakukan, didapat konsep minimalis karena produk sarana bermain kucing ini akan diletakan di dalam rumah sehingga dibutuhkannya gaya desain yang sederhana dan tidak membuat ruangan terlihat berantakan, mengingat banyaknya 
Andi Farid Hidayanto, Adinda Prita Dwisuda Putri, Desain Sarana Bermain Kucing Bernuansa Alam

komponen-komponen yang harus ada dalam sarana bermain kucing. Lebih spesifik lagi digunakan gaya desain Modern Zen. Karena gaya desain modern zen sendiri merupakan gaya dekorasi minimalis sederhana yang seringkali diterapkan dirumah-rumah Jepang tradisional untuk menciptakan suasana tenang, damai, nyaman serta dekat dengan alam. Arti kata Zen sendiri bila diartikan dalam bahasa Indonesia adalah 'Meditasi' yang artinya menciptakan ketenangan, keseimbangan, harmoni dan relaksasi.

Dari analisis-analisis warna yang telah dilakukan, maka warna yang terpilih untuk diaplikasikan pada produk sarana bermain kucing ini adalah kombinasi antara warna netral dan warna lain. Untuk bagian kerangka produk yaitu berwarna coklat, untuk tiang dan dahan menggunakan warna asli dari tali kapal yaitu coklat. Karena produk sarana bermain kucing ini berkonsep outdoor atau mengambil tema suasana luar rumah, maka warna yang digunakan adalah warna netral atau warna alam. Sedangkan untuk tempat tidur kucing untuk bagian luar diberi berwarna abu-abu dan pada bagian dalam kandang diberi warna coklat tua, karena untuk memberikan kenyamanan kucing pada saat kucing sedang berada di dalamnya. Grafis menggunakan warna CMYK, yaitu biru, merah atau kuning untuk menarik perhatian kucing.

Pada produk sarana bermain kucing, desain grafis difungsikan sebagai aksentuasi. Apabila produk diaplikasikan dengan visualisasi ilustrasi atau typografi ilustrasi dan lukisan, kurang tepat karena konsep dari produk ini adalah minimalis modern zen yang artinya sederhana dan menenangkan. Apabila diaplikasikannya visualisasi ilustrasi atau typografi dan lukisan di dalam produk, maka akan tidak sesuai dengan konsep, karena produk ini menekankan grafis yang mengacu pada bentuk, bukan berupa subjek atau tulisan. Dari analisisanlisis grafis yang telah dilakukan, yang sesuai dengan desain sarana bermain kucing ini adalah Icon, Indeks \& Simbol. Karena pada desain sarana bermain kucing ini hanya menampikan siluet jejak kaki kucing sebagai sarana komunikasi pada konsumen bahwa produk ini dibuat khusus untuk kucing karena grafis yang digunakan mirip atau memiliki hubungan dengan objek yang diwakilinya yaitu kucing, serta tidak merusak konsep yang telah diterapkan yaitu minimalis modern zen. 


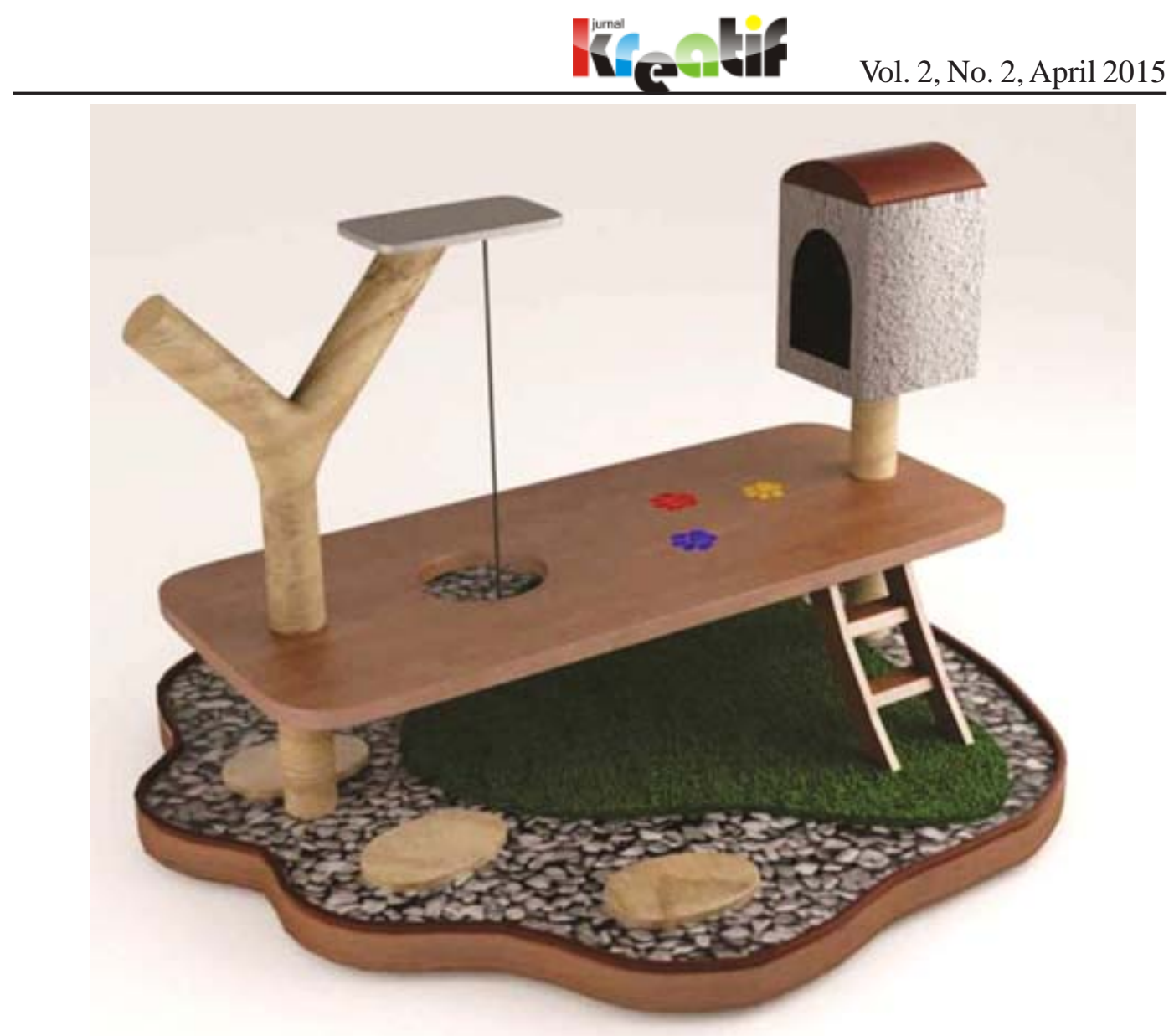

Gambar 7. Desain Akhir

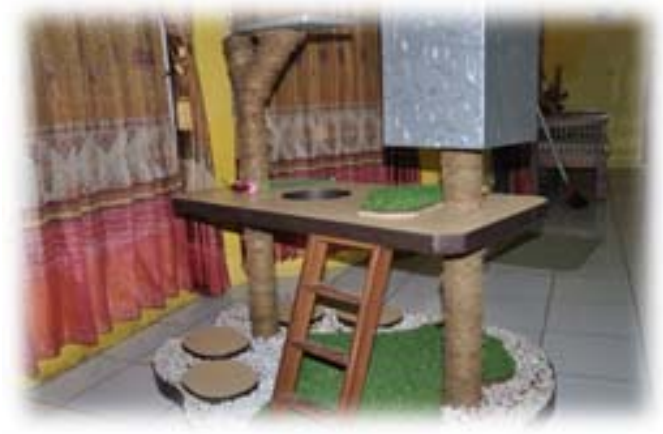

Gambar 8. Detail produk

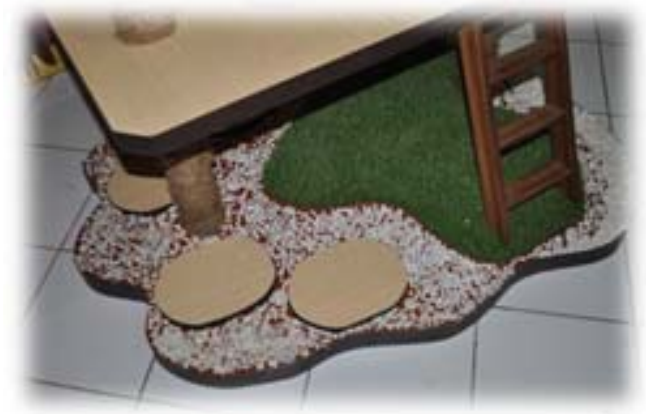

Gambar 9. Detail produk 
Andi Farid Hidayanto, Adinda Prita Dwisuda Putri, Desain Sarana Bermain Kucing Bernuansa Alam

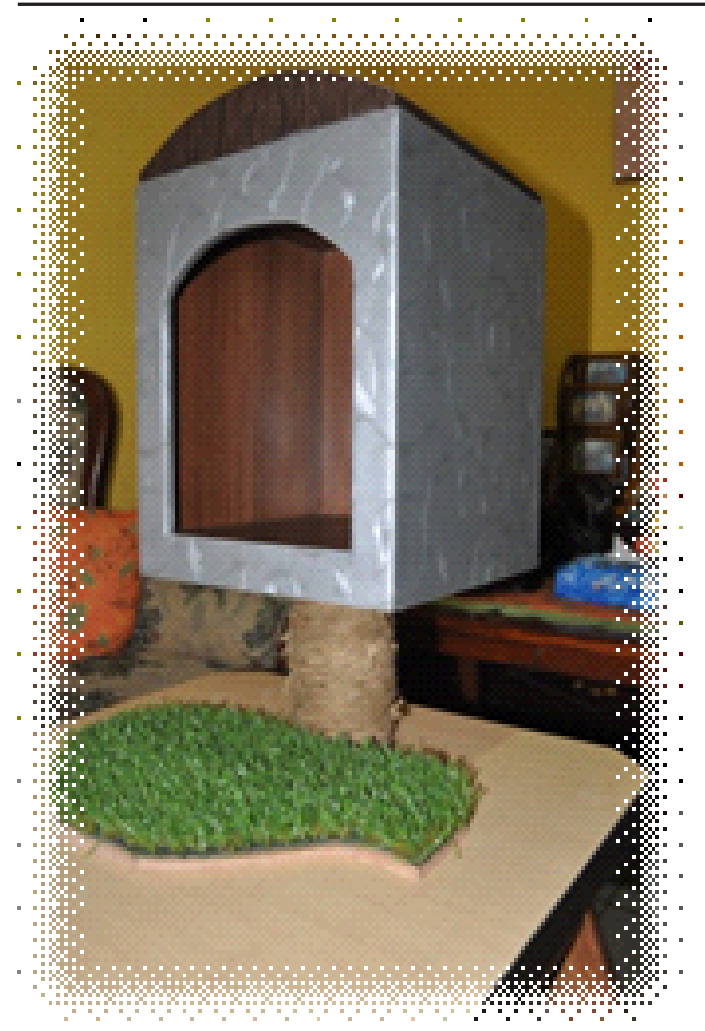

Gambar 10. Detail produk

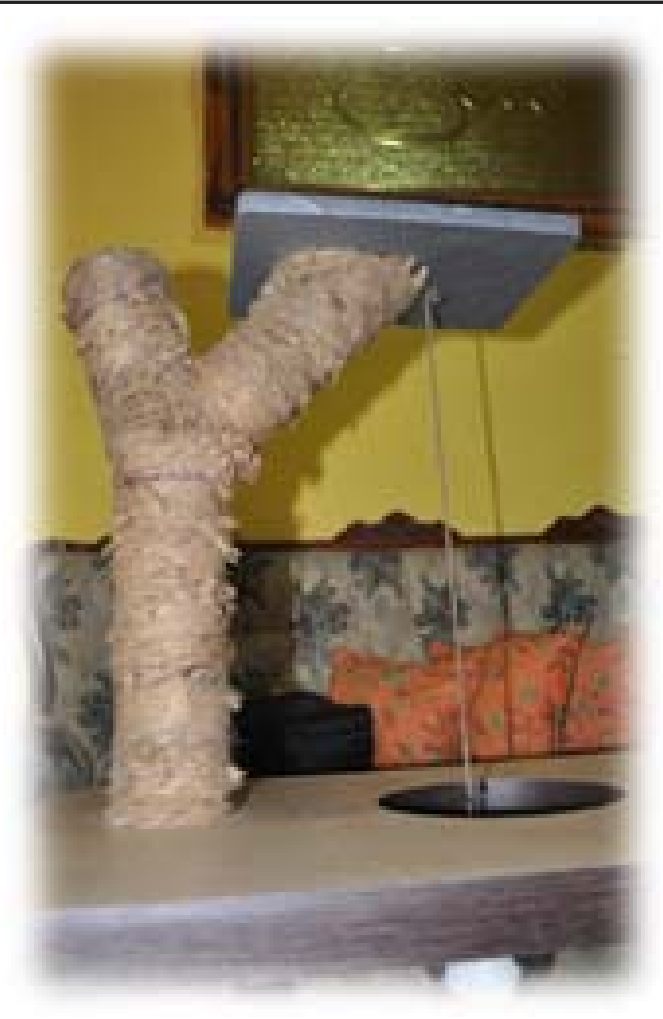

Gambar 11. Detail produk

\section{Keimpulan}

Produk sarana bermain kucing ini merupakan salah satu fasilitas untuk mempermudah kucing agar tetap melakukan segala aktifitas bermain dan mempermudah para pemilik kucing untuk membebaskan kucing bermain di dalam rumah. Sarana bermain tersebut didesain dengan sarana bermain untuk kucing sekaligus dengan fasilitas penunjangnya dan memiliki suasana seperti di luar rumah dengan adanya penambahan rumput sintetis, bebatuan dan dahan. Sarana bermain tersebut didesain dengan sistem yang sederhana dan mudah saat dioperasionalkan dan diproduksi. Warna yang diaplikasikan pada produk menggunakan warna netral karena

mengangkat tema lingkungan luar rumah, sehingga kucing menjadi nyaman ketika sedang bermain.

Saran yang dapat diberikan adalah bagi para pemilik kucing untuk memberikan fasilitas bermain yang baik sesuai dengan aktifitas kucing. Untuk para produsen agar dapat memproduksi produk yang sesuai dengan kenyamanan dan kebutuhan kucing. Produk ini masih bisa dikembangkan agar desain lebih maksimal guna memenuhi kebutuhan penggunanya, baik bagi pemilik maupun hewan piaraannya. 
DAFTAR PUSTAKA

Marizar, Eddy S. (2005). Designing Furniture Teknik Merancang Mebel Kreatif. Media Pressindo. Yogyakarta.

Nurmianto, Eko. (1996). Ergonomi Konsep Dasar dan Aplikasinya Edisi Pertama. Jurusan Teknik Industri ITS, PT Candimas Metropole, Jakarta.

Pulat, B. Mustafa (1992). Fundamentals of Industrial Ergonomic. New Jersey. Prentice Hall International

Suryana, Agus. (2007). Strategi Pemasaran Untuk Pemula. EDSA Mahkota. Jakarta.

Suyanto, M . (2004). Analisis dan Desain Aplikasi Multimedia untuk Pemasaran. Andi, Yogyakarta.

\section{WEBTOGRAFI}

. 2013. Artikel fakta tentang kucing (1 Maret 2016)

Nationalgeographic.co.id

2012. Artikel teori warna. (11 Maret 2016)

http://www.satriamultimedia.com/artikel_teori_warna.html

2009. Pengertian modern. (11 Maret 2016)

http://jalius12.wordpress.com/2009/10/18/pengertian-modren/

. 2013. Segmentasi pasar. (1 April 2016)

http://azzamkasep.blogspot.com/2013/01/segmentasi-pasar.html?m=1 